freedom from failure of $92 \%$ at 10 years. ${ }^{1}$ Obstructed pulmonary venous pathway was described as an early complication of the lateral tunnel cavopulmonary connection as a result of improper baffle creation. $^{2}$ Technical improvements have reduced this complication, and in our experience it is rare. Previous reports ${ }^{3,4}$ underline the relative greater frequency of this complication in heterotaxy syndrome when associated with anomalous pulmonary and systemic venous connections, which can make surgical repair complicated with the need to create a tortuous and potentially obstructive pathway. Despite this concern, a recent report from our institution $^{5}$ has shown excellent outcome with cavopulmonary connection in patients with heterotaxy syndrome and anomalous pulmonary venous return. This is likely due to improved surgical technique and use of extracardiac conduit in cases with complex atrial and venous anatomy $(18 \%)$.

None of the 3 patients had evidence of obstruction at the pulmonary venous pathway early after the Fontan procedure, as determined by 2-dimensional echocardiography. Pulmonary venous obstruction developed slowly through a period of several months to years. In patient 2, pulmonary venous obstruction developed 4 months after device closure of the fenestration, suggesting that the additional scarring from device implantation contributed to the obstruction. The obstruction was due to fibrotic tissue at either the interatrial septum or in the interatrial course of the pulmonary veins (patient 2).
To prevent this complication, and to ensure a wide open pulmonary venous outflow, particularly in patients with mitral atresia or stenosis, we currently enlarge the communication between the pulmonary veins and the right atrium by unroofing the coronary sinus posteriorly into the left atrium, in addition to resection of the interatrial septum.

In conclusion, late onset obstruction of pulmonary venous pathway after lateral tunnel cavopulmonary connection is a rare but serious complication that may be prevented by unroofing the coronary sinus at the time of Fontan procedure.

\section{References}

1. Stamm C, Friehs I, Mayer JE, Zurakowski D, Triedmann JK, Moran $\mathrm{AM}$, et al. Long-term results of the lateral tunnel Fontan operation. J Thorac Cardiovasc Surg. 2001;121:28-41.

2. Fogel MA, Chin AJ. Imaging of pulmonary venous pathway obstruction in patients after the modified Fontan procedure. J Am Coll Cardiol. 1992;20:181-90.

3. Uchida T, Uemura H, Yagihara T, Tsukano S, Kitamura S. Pulmonary venous obstruction after total cavopulmonary connection in heterotaxy. Ann Thorac Surg. 2002;73:273-4.

4. Berman W, Fripp JJ, Yabek SM. Late-onset pulmonary venous pathway obstruction after Fontan operation: presentation masquerading as intraatrial baffle leakage. Pediatr Cardiol. 1997;18:49-51.

5. Stamm C, Friehs I, Duebener LF, Zurakowski D, Mayer JE, Jonas RA, et al. Improving results of the modified Fontan in patients with heterotaxy syndrome. Ann Thorac Surg. 2002;74:1967-78.

\title{
Complex double-outlet right ventricle repair in a neonate with complete tracheal agenesis
}

\author{
Guido Oppido, MD, ${ }^{\text {a }}$ Carlo Pace Napoleone, MD, a Antonino Loforte, MD, ${ }^{a}$ Simonetta \\ Baroncini, MD, ${ }^{\mathrm{b}}$ Mario Lima, MD, ${ }^{\mathrm{c}}$ and Gaetano Gargiulo, MD, ${ }^{\mathrm{a}}$ Bologna, Italy
}

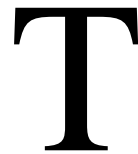

racheal agenesis is a rare malformation with fatal consequences in very early life. We report the case of a baby girl with tracheal agenesis who during early infancy underwent complete repair of her associated $\{\mathrm{S}, \mathrm{D}, \mathrm{D}\}$ double-outlet right ventricle with supracardiac total

\footnotetext{
From the Departments of Pediatric Cardiac Surgery, ${ }^{a}$ Pediatric Anesthesiology, ${ }^{\mathrm{b}}$ and Pediatric Surgery, ${ }^{\mathrm{c}}$ S. Orsola-Malpighi Hospital, University of Bologna Medical School, Bologna, Italy.

Received for publication May 21, 2003; accepted for publication June 18, 2003.

Address for reprints: Guido Oppido, MD, Department of Pediatric Cardiac Surgery, Ospedale S. Orsola-Malpighi, Via Massarenti, n.9, 40138 Bologna, Italy (E-mail: guidooppido@yahoo.com).

J Thorac Cardiovasc Surg 2004;127:283-5

$0022-5223 / \$ 30.00$

Copyright $\odot 2004$ by The American Association for Thoracic Surgery

doi:10.1016/S0022-5223(03)01298-4
}

anomalous pulmonary venous connection and is still alive at the age of 10 months.

\section{Clinical Summary}

The patient was born sponta-

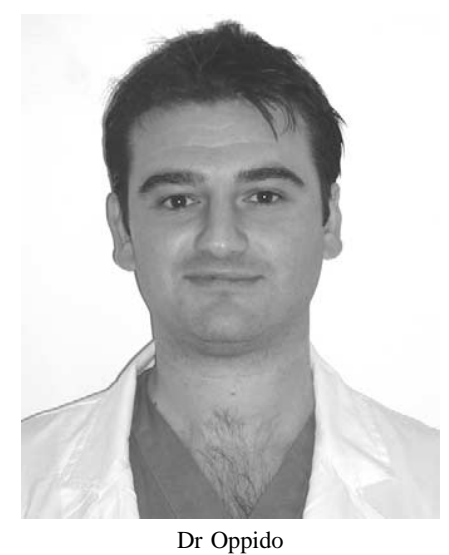
neously at a gestational age of

35 weeks. Birth weight was $2 \mathrm{~kg}$, and Apgar score at 1 minute was 2 , increasing to 6 after 2 minutes of mask ventilation. Critical clinical conditions required intubation, but the tube failed to pass the larynx under direct laryngoscopy. A blind end of the larynx was visualized with the aid of a flexible endoscope, whereas the tracheal bifurcation could be visualized from the distal esophagus through a tracheoesophageal fistula. A Portex 3 tube (Portex, Inc, Keene, $\mathrm{NH}$ ) was positioned through the esophagus into the fistula, achieving a satisfactory bilateral ventilation.

Helical TC scan showed complete agenesis of the trachea (Floyd type II) with a distal tracheoesophageal fistula (Figure 1). Echocardiography showed $\{S, D, D\}$ double-outlet right ventricle (with subaortic ventricular septal defect), total anomalous pulmo- 


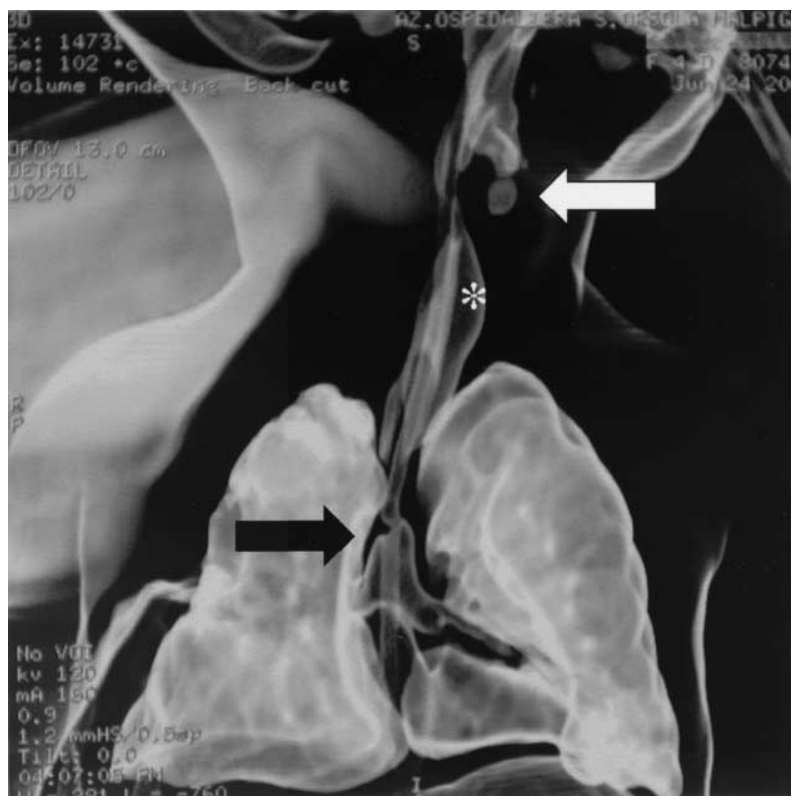

Figure 1. Helical computed tomographic scan showing complete congenital absence of trachea from larynx (white arrow) to bifurcation arising from tracheoesophageal fistula (black arrow). Asterisk indicates esophagus.

nary venous connection to the right superior vena cava, and unrestricted atrial septal defect.

After 30 days, the patient underwent a complex palliative operation to separate the airway from the alimentary tract, consisting of (1) division of the esophagus below the fistula and gastrostomy (for alimentation), (2) gastroenteroanastomosis (to resolve pylorus and proximal duodenal atresia), (3) Merkel diverticulum resection, and (4) double cervical esophagostomy. The proximal esophagostomy was created to divert salivary secretion protecting the airway; the distal esophagostomy was used as the entrance of the newly created airway, after positioning a 10 by 50-mm Rusch Polyflex esophageal stent (Rusch Inc, Duluth, Ga) to keep the esophagus air patent. A tracheostomy 5.5-mm (external diameter) Shiley cannula (Shiley, Inc, Irvine, Calif) was positioned through the lower esophagostomy into the stented esophagus, connecting the infant to the ventilator (Figure 2).

Because of failure to thrive and severe cyanosis, the infant underwent catheterization, which confirmed the cardiac diagnosis. Complete surgical repair was carried out, consisting of (1) intracardiac left ventricle-aorta pericardial baffling, (2) right superior vena cava division (above the drainage of the four pulmonary veins); (3) intra-atrial pericardial patch baffling of the right superior vena cava orifice (draining all four pulmonary veins) to left atrium through the atrial septal defect, and (4) anastomosis of the proximal right superior vena cava to the right atrial appendage. Cardiopulmonary bypass and cardioplegic cardiac arrest times were 166 and 94 minutes, respectively, and body temperature was lowered to $26^{\circ} \mathrm{C}$. The child was taken to the postoperative cardiac intensive care unit and could be weaned from mechanical ventilation at 7 days.

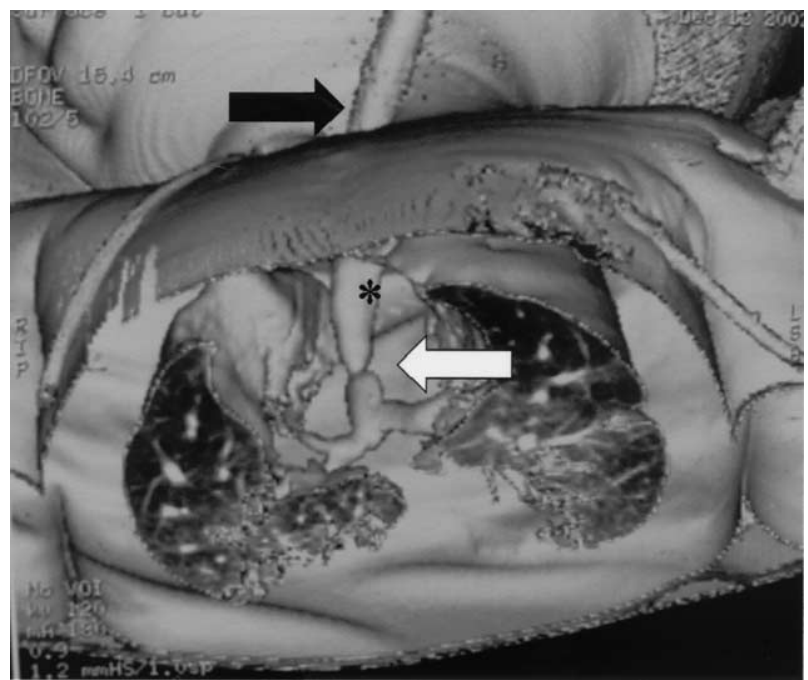

Figure 2. Three-dimentional reconstruction of helical computed tomographic scan after palliative operation accomplished to separate airway from alimentary tract. Stent keeps esophagus air patent, guaranteeing adequate ventilation. Tracheostomy cannula (black arrow) has been inserted through distal esophagostomy into stented esophagus (asterisk). Esophagus has been divided just below level of tracheoesophageal fistula (white arrow).

Currently the patient is 10 months old and is waiting for airway and alimentary tract surgical reconstruction. Her hemodynamic status is unremarkable, and she has gained weight, being now in the 50 th percentile.

\section{Discussion}

Tracheal agenesis, or congenital absence of the trachea, is a very rare malformation accounting for less than 1:50000 live births. ${ }^{1}$ It was first described in 1900 by Payne. ${ }^{2}$ Since that time, fewer than 100 cases have been reported in the literature.

According to Floyd and coauthors ${ }^{3}$ tracheal agenesis is classifiable into three anatomic subtypes: type I, agenesis of the proximal trachea, with a normal distal trachea connected to the esophagus through a tracheoesophageal fistula; type II, complete agenesis of the trachea, with the two main stem bronchi fused in the midline at the carina, which arises from a tracheoesophageal fistula; and type III, complete agenesis of the trachea, with the two main stem bronchi arising separately from the esophagus. Associated congenital malformations and congenital heart disease account for $90 \%$ and $70 \%$, respectively, of the cases reported in the literature. ${ }^{4}$ Some authors refer to tracheal agenesis as part of multimalformation syndromes, such as VA(C)TER(L) (vertebral anomalies, anal atresia, cardiac abnormalities, tracheoesophageal fistula or esophageal atresia, renal agenesis and dysplasia, limb defect) and TACRD (tracheal agenesis or atresia, complex congenital cardiac malformations, radial ray defects, duodenal atresia) syndromes. $^{4,5}$

Clinical presentation is characterized by rapid onset of severe respiratory distress at birth, absence of audible crying, and impos- 
sibility of endotracheal intubation. Survival is due to either 'incidental' endoesophageal intubation or prompt surgical tracheostomy (Floyd type I).

Surgical repair or palliation of associated congenital cardiac lesions has been never described in the literature, because most affected patients usually die before any attempt at surgical intervention. This is the first patient to our knowledge to survive palliation of the respiratory tract malformation as well as definitive intracardiac repair. She is now thriving and is currently being evaluated for definitive surgical reconstruction of the airway and alimentary tract.

\section{References}

1. Manschot HJ, van den Anker JN, Tibboel D. Tracheal agenesis. Anaesthesia. 1994:49:788-90.

2. Payne WA. Congenital absence of the trachea. Brooklyn Med J. 1900; 14:568.

3. Floyd J, Campbell DC, Dominy DE. Agenesis of the trachea. Am Rev Respir Dis. 1962;86:557-60.

4. van Veenendaal MB, Liem KD, Marres HA. Congenital absence of the trachea. Eur J Pediatr. 2000;159:8-13.

5. Evans JA, Reggin J, Greenberg C. Tracheal agenesis and associated malformations: a comparison with tracheoesophageal fistula and the VACTERL association. Am J Med Genet. 1985;21:21-34.

\title{
Formation of a stenotic fibrotic membrane at the distal anastomosis of bovine jugular vein grafts (Contegra) after right ventricular outflow tract reconstruction
}

\author{
Alexander Kadner, MD, ${ }^{a}$ Hitendu Dave, MD, ${ }^{a}$ Thomas Stallmach, MD, ${ }^{\mathrm{b}}$ Marko Turina, MD, and René Prêtre, MD, \\ Zurich, Switzerland
}

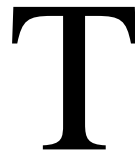

he surgical correction of many congenital right ventricular outflow tract (RVOT) anomalies necessitates the interposition of an extracardiac valved conduit. A variety of conduits have been used, and a few years ago the xenogenic valved conduit Contegra (Medtronic, Inc, Minneapolis, Minn) was introduced into clinical practice. ${ }^{1-3}$ The graft consists of a jugular bovine vein segment containing a native trileaflet valve. It presents several advantages relative to other available conduits because it demonstrates a high pliability of the graft tissue, provides abundant conduit material proximal and distal to the valve for RVOT reconstruction, and is readily available in a large range of sizes.

Although a few reports have been published, little information exists regarding the fate of the conduit after implantation. The resection of 2 Contegra grafts in our experience amounting to 67 implantations prompted us to report these cases and to analyze the reason for conduit failure.

\section{Clinical Summary}

Between May 2001 and January 2003, the Contegra conduit was implanted in 67 patients for RVOT reconstruction, including cor-

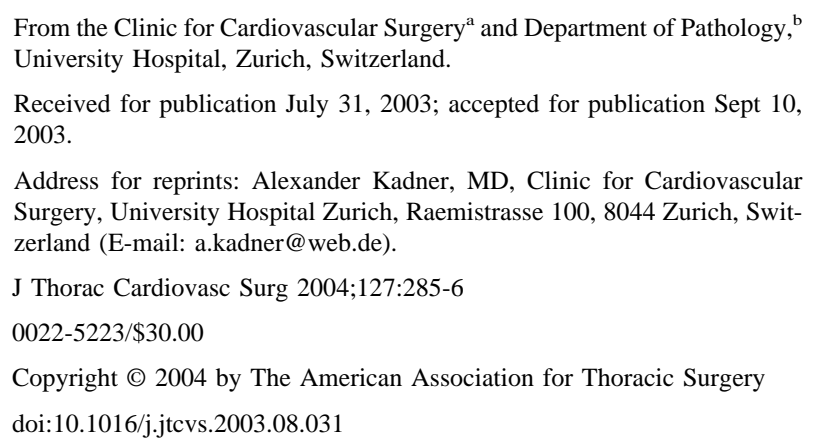

rection of tetralogy of Fallot and pulmonary atresia $(n=34)$, Ross procedure $(n=17)$, correction of truncus arteriosus $(n=7)$, Rastelli procedure $(n=4)$, and other procedures $(n=5)$. Routinely performed intraoperative and postoperative echocardiography demonstrated excellent conduit performance in all patients. At 12 and at 8 months after implantation, however, 2 patients $(3 \%)$ showed increasing pressure gradients as great as $50 \mathrm{~mm} \mathrm{Hg}$ at the distal anastomoses and eventually required reoperation with graft replacement (Figure 1, A). Both patients had undergone repair of tetralogy of Fallot with a 12-mm Contegra conduit, which was selected because of the patients' diminutive pulmonary arteries.

\section{Pathologic Findings}

Macroscopic inspection revealed the formation of an internal annular membrane anchoring at the level of the distal anastomosis, with proximal extensions into the valve sinuses in both explanted grafts. The valve leaflets were unaffected and well preserved (Figure 1, B).

Histologic analysis demonstrated a fibrinous composition of the membranes partially covered with granulation tissue and the preservation of the collagen structures of all three vessel wall layers of the conduits with, however, a reduced density of the medial collagen fibers. The infiltration with lymphocytes and macrophages was observed in all layers but was predominantly in the adventitia and on the internal lumina of the grafts.

\section{Discussion}

Because of the recent introduction of the Contegra conduit, experiences regarding its long-term performance are limited, and until now only a single conduit failure, an aneurysmal dilatation, has been reported. ${ }^{4}$ Here we report 2 cases of conduit failure from the formation of an intimal membrane that led to severe RVOT stenosis at 8 and 12 months after implantation. Both patients had been treated for tetralogy of Fallot and severe hypoplasia of the pulmonary arteries and had received the smallest available conduit size 